\title{
Positioning of EU-15 Member States in ACCORDANCE With THE DEVElopMent STAGE OF INFORMATION SOCIETY AND ALLOCATED FUNDS FROM STRUCTURAL FUND
}

\author{
KAFOL, C.
}

Abstract: There has been a lot of discussion in connection with the achieving the goals set forth in Lisbon Strategy which enhances ICT (Information and Communication Technologies) as one of the crucial pillars for the future development of economic growth and increased competitiveness of the European Union. Resolution on the future EU policy on ICT has been accepted and is dealing with the issues within Government, citizen's coping with the use of ICT, development of innovative industries and new digital services, development of new broadband technologies and networks and electronic communication safety. EU is developing methods for measuring effectiveness of fund allocation from Structural Funds to member states. In this article we suggest the methodology for positioning of member states according to the state of development of information society in correlation with allocated funds from Structural Funds which may be a foundation for development of a complex methodology. Presented policy comprises the period 2002-2012.

Key words: information society, structural funds, effectiveness, development
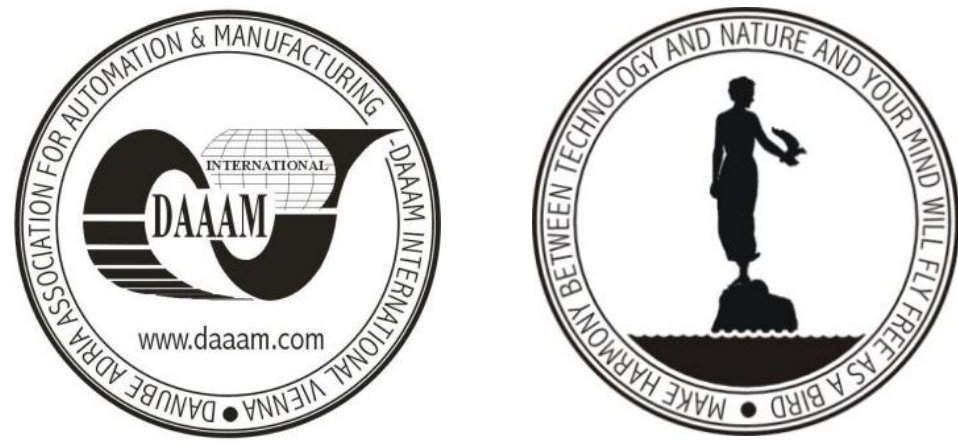

Author's data: M. Sc. Kafol, C[iril]; Telekom Slovenije, d. d., Cigaletova 15, SI 1000 Ljubljana, Slovenia, EU, cirilkafol@volja.net

This Publication has to be referred as: Kafol, C[iril] (2012). Positioning of EU-15 Member States in Accordance with the Development Stage of Information Society and Allocated Funds from Structural Fund, Chapter 12 in DAAAM International Scientific Book 2012, pp. 129-142, B. Katalinic (Ed.), Published by DAAAM International, ISBN 978-3-901509-86-5, ISSN 1726-9687, Vienna, Austria DOI: $10.2507 /$ daaam.scibook.2012.12 
Kafol, C.: Positioning of EU-15 Member States in Accordance with the Developm...

\section{Introduction}

European Structural funds can be a significant bridge in transition of certain states to an information society. For the countries separately and the European Union correctly and efficiently to allocate funds in different fields of activities, the party allocating the funds must have an insight over the efficiency in allocation of funds. In the area of information society, the European Union has established a measuring system of development with indicators relatively late in 1997. In literature there are many methodologies to measure funds allocation efficiency, which are not limited to phenomenon of transition to an information society, but they analyze the impact of Structural Funds on well-being to individual members. Some authors maintain that the Structural Funds have a marginal impact on realistic convergence in the European Union (Boldrin \& Canova, 2001) (Midelfart, 2004). The majority of studies use methods of growth regression which have methodological, econometric and data irregularities. The assessment of state aid is relatively rear, though the scope of the above described effects have registered certain studies which were based on researches in enterprises that have received funds (Gerling, 2002).

To follow the effects of a cohesive policy of the European Union there are two main methods established as follows: a model of simulation and a model of econometric growth regression, which include the size of funds allocated as an explanatory variable. A large number of macroeconomic models arising from theoretic bases are used to assess the impact of Structural Funds. An interim model of optimal growth was developed in order to explain the impact on Greece, Portugal, and Ireland. The European Commission backs mostly on two combined models (supply and demand), called QUEST II and Hermin.

The standard statistical methods of growth regression, which measure the absolute or conditional $\beta$-convergence, may not provide evidences on the impact, or on efficiency of the European Union cohesive policy. Correlation cannot be found between the appearance of convergence, or absence of convergence and/or between the process speed and intensity of co-financing from the Structural Funds, since convergence is a resultant from many economic, social, and political factors and not only function of the European Union aid (Draft Chapter 2 of European Economy: Catching-up, growth and convergence of the new members, 2004).

The problem of monitoring of efficiency to allocated funds is always present in the systems of projects co-financing. Equally problematic is the discovery of development in the field of information society because the indicators are mainly composed of soft factors that are hardly measurable, and also because the data collection started as early as in the late nineties and for that it is impossible to evaluate long-term trends. Literature may not discover the positioning of certain states in terms of information technological development and the receipt of funds from European Funds out of which the largest is the Structural Fund.

In context of stimulating the transition to information society, methodology needs to be produced to monitor the effects of funds allocation from Structural Funds. Monitoring the effects, the party allocating the funds obtains information enough to adjust to competitive conditions regarding allocation of funds and to maximization of 
desired effects. This article is the first step in developing of a new monitoring fund efficiency method in information society.

The objective of the article is positioning of states from EU-15 in terms of information society development and of funds allocated from Structural Funds as well as examining by statistic methods the variant covariant links among indicators selected for economic and information success of European Union states. The fundamental issue is whether more funds from the Structural Funds are allocated in information less developed countries, or this assumption is not true and if we can position the country receiver in a double dimensioned matrix with regard to the indicator of funds received and the structural fund and the indicator of information development.

Literature has no explicit data how certain countries are positioned in terms of information technological development and in receiving of funds from European funds of which the largest is the Structural Fund. In this context, I have decided to analyze the variance covariant matrix of selected indicators of resources received from the largest Structural Fund.

On the basis of the variables, the indicators selected regarding development of information society I have examined the positions or positioning of certain countries as well as the impact or role of the variable that determines the value of resources received from the EU Structural Fund.

The basic assumption is that there exist an inverse proportional link between allocated money from funds and information communication development in certain countries.

From all indicators provided by EU with regard to measuring of development in information society, roughly speaking, out of 33 indicators (this is not completely valid since some indicators are derived, and others are not indicators, however, represent results from investigations), we have separated to analyze six indicators for information society and one indicator that shows value of money received from Structural Funds, seven indicators in total as follows:

- Information and Communication Technology (ICT) balance of trade (2002, in \% GDP at market prices) - see A (in Table 1),

- Number of internet users (2002, number of internet users per 100 inhabitants) - B,

- Number of subscribers in mobile telephony (2002, number of subscribers in mobile telephony per 100 inhabitants) - C,

- Usage of personal computers and internet in households (new 2002, percentage of households having an access to internet) $-\mathrm{D}$,

- Number of computer experts (2002, computer experts as a percentage of totally employed inhabitants) - E,

- Level of e-Government (November 2002, percentage of people contacting the state by internet as a medium) $-\mathrm{F}$,

- Value of actually obtained funds from EU Structural Funds (2002, in Euro/inhabitant) - G.

Roughly speaking, this means that we have used approximately $18,1 \%$ of all indicators that EU covers in the area of information society.

Our indicators are selected in accordance with the principle as follows: 
Kafol, C.: Positioning of EU-15 Member States in Accordance with the Developm...

- Availability (must exist for the year 2002),

- Representation and relevance (to describe to a sufficient extent our phenomenon, we are interested in the representation and relevance in the field of information society and not for exp. structure of usage and etc.). For this, I am selecting indicators showing absolute numbers, relevant for the examined phenomenon.

All six indicators of information society we shall use in the model together with the indicators regarding the allocated funds from the 2000 EU Structural Funds. Complete data for analysis $(\mathrm{A}-\mathrm{G})$ are provided in Table 1.

\begin{tabular}{|l|c|c|c|c|c|c|c|}
\hline Country (EU-15) & A & B & C & D & E & F & G \\
\hline Austria & $-0,7$ & 41 & 83 & 54 & 1,9 & 49 & 32,02 \\
\hline Belgium & $-0,7$ & 33 & 79 & 43 & 1,9 & 59 & 37,03 \\
\hline Denmark & $-0,5$ & 47 & 83 & 67 & 2,4 & 64 & 23,37 \\
\hline Finland & 4,0 & 51 & 85 & 55 & 2,4 & 40 & 104,61 \\
\hline France & $-0,3$ & 31 & 65 & 36 & 1,8 & 58 & 42,28 \\
\hline Germany & $-0,2$ & 42 & 72 & 46 & 1,6 & 54 & 45,56 \\
\hline Greece & $-1,2$ & 28 & 84 & 14 & 0,5 & 48 & 231,24 \\
\hline Ireland & 6,6 & 27 & 76 & 57 & 1,5 & 44 & 182,96 \\
\hline Italy & $-0,8$ & 30 & 93 & 35 & 1,2 & 42 & 88,57 \\
\hline Luxemburg & 1,1 & 37 & 101 & 54 & 1,7 & 54 & 22,73 \\
\hline Netherlands & 0,1 & 53 & 72 & 68 & 3,1 & 59 & 29,84 \\
\hline Portugal & $-0,8$ & 36 & 82 & 31 & 0,9 & 42 & 216,31 \\
\hline Spain & $-1,0$ & 19 & 82 & 31 & 1,1 & 47 & 95,88 \\
\hline Sweden & 0,6 & 57 & 89 & 66 & 3,3 & 71 & 25,89 \\
\hline United Kingdom & 0,0 & 41 & 84 & 50 & 2,2 & 51 & 49,34 \\
\hline
\end{tabular}

Tab. 1. Relevant EU-15 data for analysis of convergence

\section{Methodological explanation of variables and bases for selection}

\subsection{ICT export, import and balance of trade (ICT foreign trade)}

Between 1997 and 2000, ICT export went up at an annual average rate of $18 \%$ and was 125 billion Euros in the year 2000. In 2001 the export was dropping at an annual average rate of 2,8 \%, in 2002 for as much as from $24 \%$ to 92 million Euro, a little bit above the export reached in 1999. Only Finland recorded increase in ICT export in 2002 at an annual average rate of $12,9 \%$, but after the decrease in export in 2001 by $27,6 \%$ (Eurostat - European Union Commission, 2002).

In 2002 ICT export was $9,3 \%$ on average of the total export of EU-15 countries, though in some countries that \% was substantially higher: Ireland $(21,5 \%$, percentage of ICT export in the total Irish export), Finland (21,7\%), and Luxemburg $(22,8 \%)$. Among the candidate countries (current members) differentiate Hungary at $26,1 \%$ and Malta at $60 \%$. Slovenia is in the lower quarter at 4,9\% ICT export in the total own export (Eurostat - European Union Commission, 2002).

In 2002 ICT import was estimated to Euro 130 billion. A similar export dropping trend was noticed also with ICT import which was $24,2 \%$ in 2002 in 
comparison to 2001. Among the EU-15 countries only Denmark recorded a slight growth in import in the year $2002(1,1 \%)$, whereas Ireland the highest decline in the amount of 43,2 \% (Eurostat - European Union Commission, 2002).

The balance of trade to EU-15 countries is negative since the import exceeded the export by more than Euro 30 billion each year in the period from 2002 to 1997. The foreign trade deficit reached the maximum in 2000 where it amounted Euro 62 billion and decreased to Euro 37 billion in 2002. The decline in trade deficit was the result of decrease in ICT import in relation to export in a relative and absolute range.

In 2002 Ireland and Finland recorded the highest trade surpluses within the EU15 countries for exp. 6,6\% and 4,0 \% compared to the national GDP, respectively. In other countries ICT foreign trade deficit or surplus was close to or lower than $1 \%$ of GDP in certain countries (Eurostat - European Union Commission, 2002).

Slovenia recorded $4,9 \%$ share in ICT export in the total export (2001 export data; the data is nearly $52 \%$ of the average in the EU-15 countries), because no data exist regarding the export in the year 2002), 7,3\% share of ICT export in the total export (data from the year 2001; the data is nearly $56 \%$ of the average in the EU-15 countries), and $1,5 \%$ i.e. foreign trade deficit in size of $1,5 \%$ (amounting nearly 27 $\%$ out of the average in the EU-15 countries i.e. lower by $1,1 \%$ than the average in the EU-15 countries) (Information Society Statistics, 2003).

Data in category 2 relate to EU-15 countries for the period between 1997 and 2002 and because of that, sufficient data for analysis may be obtained. We have selected indicator ICT balance of trade as the most appropriate since it represents a good indicator regarding the development and specialization in ICT sector for certain countries. To distinguish the impact on the size of each national economy, it was selected the ICT Trade Balance as a percentage of GDP at market prices in \%.

The index selected shall be a varying information society 1 in the model.

\subsection{Number of internet users}

The number of internet users in 2002 was estimated to 135 million in the EU-15 countries, which means that approximately one third of population used internet. The largest number of internet users among the EU-15 countries was in the Scandinavian countries mostly in Sweden (57 out of 100 inhabitants), and in Netherland (53 out of 100 inhabitants). The lowest number of users was recorded in Greece and Spain, being the only countries with the lower than 20 users out of 100 inhabitants. The comparison among the country-candidates demonstrates that only Estonia (41 user out of 100 inhabitants), and Slovenia (40 users out of 100 inhabitants) exceed the average in the EU-15 countries (Information Society Statistics, 2003).

The indicator is, because of the data availability and foreseen correlation with EU funds, suitable for further analysis. To distinguish the size of the country we shall use data regarding the number of internet users per 100 inhabitants that actually is a percentage of population using internet.

\subsection{Number of subscribers in mobile telephony}

In 2002, the EU-15 countries had 298 million subscribers in mobile telephony which means $79 \%$ market coverage (in relation to all inhabitants). The number of 
Kafol, C.: Positioning of EU-15 Member States in Accordance with the Developm...

subscribers increased highly from 2000 to 2002, and in some countries there was saturation (Italy, 93 out of 100 inhabitants), and Luxemburg (101 out of 100 inhabitants). Data should also take into account that all subscriptions were included but not only the active, and also that some subscribers were subscribed with more than one offering party i.e. that they paid more than one subscription and for this reason data per inhabitants is not quite true (Information Society Statistics, 2003).

In some candidate countries (present members), the number of subscribers is comparable with EU-15 countries such as for exp. Czech Republic, Slovenia and Malta. In Slovenia the number of subscribers per 100 inhabitants in 2002 was 84, in 2001 the number was 74 in 2000 the number was 61. A high growth was noticeable from 2000 to 2002 (Information Society Statistics, 2003).

The number of subscribers in the mobile telephony can be measurable data since the offering parties have a very good oversight on the number of subscribers. Although the link is disputable for money allocation from EU funds, it is one of the indicators to information society and we classify it in the relevant indicators.

\subsection{Use of personal computers and internet in households}

In September 2000, half of population on average in the EU-15 countries used personal computers despite that under the average values in some countries were noticed: Spain (37\%), Portugal (32\%), and Greece (29\%). Above the average use was noticed in Netherland, Sweden, and Denmark where the average ranged about three thirds of population (Eurostat-European Union Commission, 2002).

A similar percentage of population was connected to internet on average where $53 \%$ of population in the EU-15 countries used internet (Eurobarometer, November 2002). The majority of that population used internet from their homes (43\% households had an access to internet), whereas the access is usually from an office, an educational institution, and an internet café.

Data are taken from Eurobarometer 88, 103, 112, 125, 135 dated October 2000, June 2001, November 2001, May/June 2002 and November 2002 and obtained by virtue of a survey. It must be taken into consideration that data is an assessment to present situation at the time of survey and taken in November (not at the end of the summer). The indicator selected \% for households with an access to internet is a good measure for penetration of ICT and use of ICT in households and to this effect it is appropriate for analysis and correlation with EU funds (Information Society Statistics, 2003).

\subsection{Number of computer experts}

In 2002 in the EU-15 countries, the computer experts were 1,7\% on average out of all employees. The larger number of countries recorded increase in computer experts in comparison to the total employees from 1998 to 2000. This trend slowed down and fully turned downwards in 2001 and 2002 as a consequence of market reality (lag of growth in the field of technological enterprises) and of an end to incremented scope of work due to the problem in 2000 (Millenium bug). Denmark and Finland had above the average share in computer experts in the total labour force 
$(2,4 \%)$ the same as Netherland $(3,1 \%)$, and Sweden $(3,3 \%)$ (Information Society Statistics, 2003).

The number of computer experts in the number of totally employed demonstrates support to components related to knowledge in information society, data were accessible and completed from 1998 to 2002, and because of this the indicator is higher for further processing.

\subsection{Rate of e-Government}

By increasing the number of households using internet also increases population communicating with public administration by an e-medium. In November $2002,52 \%$ of population in EU-15 countries contacted the public administration by internet in comparison to $46 \%$ in the previous year (Information Society Statistics, 2003). An appropriate indicator would be the percentage of people who anytime contacted public administration by internet, but since it is impossible to express explicitly from the Table, we must calculate it.

From the Table with the percentage of people who have used internet to contact the public administration (divided into purposes), we have obtained data that is provided for the percentage of people who never contacted public administrative institutions by internet. Making conclusion on this basis, the remaining to $100 \%$ represents our indicator requested. The Table may explicitly provide us the data by calculating of $100-x$ (for exp. EU-15, never contacted by Internet, 54; our calculation is $100-54=46 \%$ and demonstrates us the percentage of people who have contacted institutions of public administration by Internet and ever contacted by internet, respectively).

\subsection{Actually allocated funds from EU Structural Funds per capita}

We have placed the actually funds in the variable allocated from the Structural Funds per capita. The data for reserved and actually allocated funds from the Structural Funds per capita may vary significantly as in question is a difference between the allocation and usage of funds. The differences occur due to payment of resources that have been reserved in the previous year, payments in advance for the reason of different time schedule of projects, overdue payments for time delay of withdrawal of project funds and etc. (European Commission, 2003).

All data are stated in Table 1.

\section{Results from calculations and findings}

We shall analyze in this Section the results obtained according to method of principal components, derived from statistical program package SPSS 11.5 (Evaluation version) and we shall provide conclusions from analysis. All results from calculations are listed in Appendix.

\subsection{Analysis of results obtained}

In our study (with SPSS 11.5) we used a method of Principal Component Analysis. Results are listed in Appendix. 
Kafol, C.: Positioning of EU-15 Member States in Accordance with the Developm...

From the data of Descriptives we see that all seven indicators have pretty different average value and standard deviation (Table 2). Therefore, data need to be standardized for further analysis as follows:

$$
z=(y-\mu) / \sigma
$$

where:

$$
\begin{aligned}
& \mu-\text { Mean value, } \\
& \sigma-\text { Standard Deviation. }
\end{aligned}
$$

This way we have obtained standardized variables $(Z x x x)$. We further insert these variables in the model and determine the correlation matrix, we make Bartlett test (regarding the level of connectivity of variables), we get the level of contents for certain variable in the principle components, the level of total variant, we draw a chart of own component values, matrix of component/s and in the end by virtue of the two principal component we draw the chart according to states.

\subsection{Descriptives - descriptive variables}

In the model with standardized variables the mean value is 0 , while the standard deviation is 1 , by which we confirm that calculations of standardized variables are correct (Table 3).

\subsection{Correlation matrix}

We notice several interesting characteristics in correlation. All correlations between standardized variable $E U \_S K L$ and other variables are negative. This fact is relatively understandable because the states which are information insufficiently developed get more resources from the Structural Funds rather than better developed countries, and for that the strongly negative correlation is natural. An exception is not the variable ZST_MO, which is weakly connected with almost all variables (both positive and negative), except for $E U \_S K L$. This confirms the fact that funds are indented also for development of mobile networks. The reason for weak correlation with other indicators is most probably the technical and the contents unconnected development of mobile telephony with the development of information society. The mobile telephony and its dramatic growth over the recent years is not a key drive to information society as we greatly associate it with information systems and internet that enables development of application automatic and data processes in contrast to mobile telephony that is still to a large extent transmission of voice.

Variables ZST_INT are very strongly related (Number of internet users), and $Z S T \_I N T \_A$ (percentage of internet users in households), which is expected, based on that we are speaking about evidently connected variables because the last is a cross section of the first. A stronger correlation we have with the variables ZST_INT (Number of internet users) and ZST_RAC_ST (number of computer experts as a percentage of all employees), which is natural for the reason that the computer experts are a component of knowledge that is a necessary prerequisite for development and maintenance to computer applications and internet, either (Table 4). 
Interesting is the mean strong correlation between variables ZTB_GDP (ICT balance of trade) and ZST_INT_A (a percentage of internet users in households). The greater surplus i.e. in this context a more developed industry for information communications technology means also a greater penetration of internet, as typical ICT representatives in households. A similar link exists also with variables ZST_INT and ZST_RAC_ST (number of computer experts as a percentage (\%) of all employees), but it is weaker.

We notice medium correlation also between variables $Z E \_G O V$ (percentage of people who contact the government administration by internet media), and $Z S T \_R A C \_S T$ (number of computer experts as a percentage of all employees). The bigger the percentage of computer experts among all employees is, the more people contact the government administration. The reason is likely in the higher awareness to people and better services that the greater number of computer experts render.

\subsection{Bartlett test}

The Bartlett test of zero hypothesis assumes that the examined variables are interconnected as follows:

$$
\mathrm{H}_{0}: P=I \quad \mathrm{H}_{1}: P \neq I
$$

In our example $P=0$, means that the differences are highly characteristic and we may reject zero hypothesis i.e. to conclude that the examined variables are not independent among each other (Table 5).

\subsection{Communalities}

In the principal component all variables are highly included except for $Z S T \_M O B$ (number of subscribers in mobile telephony) that is understandable bearing in mind the fact that the correlation with other variables is negligible (Table 6). It is interesting that the variables $Z S T \_R A C_{-} S T$ are the least damaged (computer experts as a percentage of the totally employed among population), and ZST_INT_A (percentage of internet users in households).

\subsection{Clarification of total variant (version) and number of components}

We are explaining $71,265 \%$ with the two components from the phenomenon; we can see from the chart Screen Plot (Fig. 3) that in the first two component, which have value above Eigenvalues $=1$ own value, we can already describe the observed phenomenon. According to Keiser's rule we see $\left(\sigma^{2} \geq 1\right)$ that to describe the observed phenomenon two components are sufficient (Table 7 and Table 8).

\section{Actual EU activities and funding in ICT field}

The European Commission aims to make sure ICTs (Information and Communication Technologies) contribute to the development of a more sustainable Europe and is, therefore, focusing on Energy Efficiency, Water Management and Climate Change Adaptation. The ICT industry must develop a framework to measure its energy and environmental performance and set itself energy efficiency targets. 
Kafol, C.: Positioning of EU-15 Member States in Accordance with the Developm...

ICTs can enable a better use of energy in buildings, transport, street lighting etc. It can also facilitate the integration of locally generated renewable energy into the electricity grid. Because of the positive role ICTs can play in helping cities reduce their carbon emissions the European Commission co-finances initiatives and research in this area through the $7^{\text {th }}$ Framework Programme for Research and Technological Development and the Competitiveness and Innovation Programme.

The effective management of water is becoming more and more important as the world's supply of clean, fresh water is steadily decreasing. ICTs are an important enabler to help improve the management of this valuable natural resource. They could do so through advanced metering technologies which would for example allow for real-time communication of consumption patterns or through innovative demand forecasting technologies to name just a few examples (Worthington, 2011).

ICT can provide a range of tools to better manage climate change, environmental data and risks. ICT can help improve the connectivity of environmental information systems across Europe and to develop web-based systems for better environmental management. This helps mitigate the impacts of climate change on the population, utilities and infrastructures (Fig. 1).

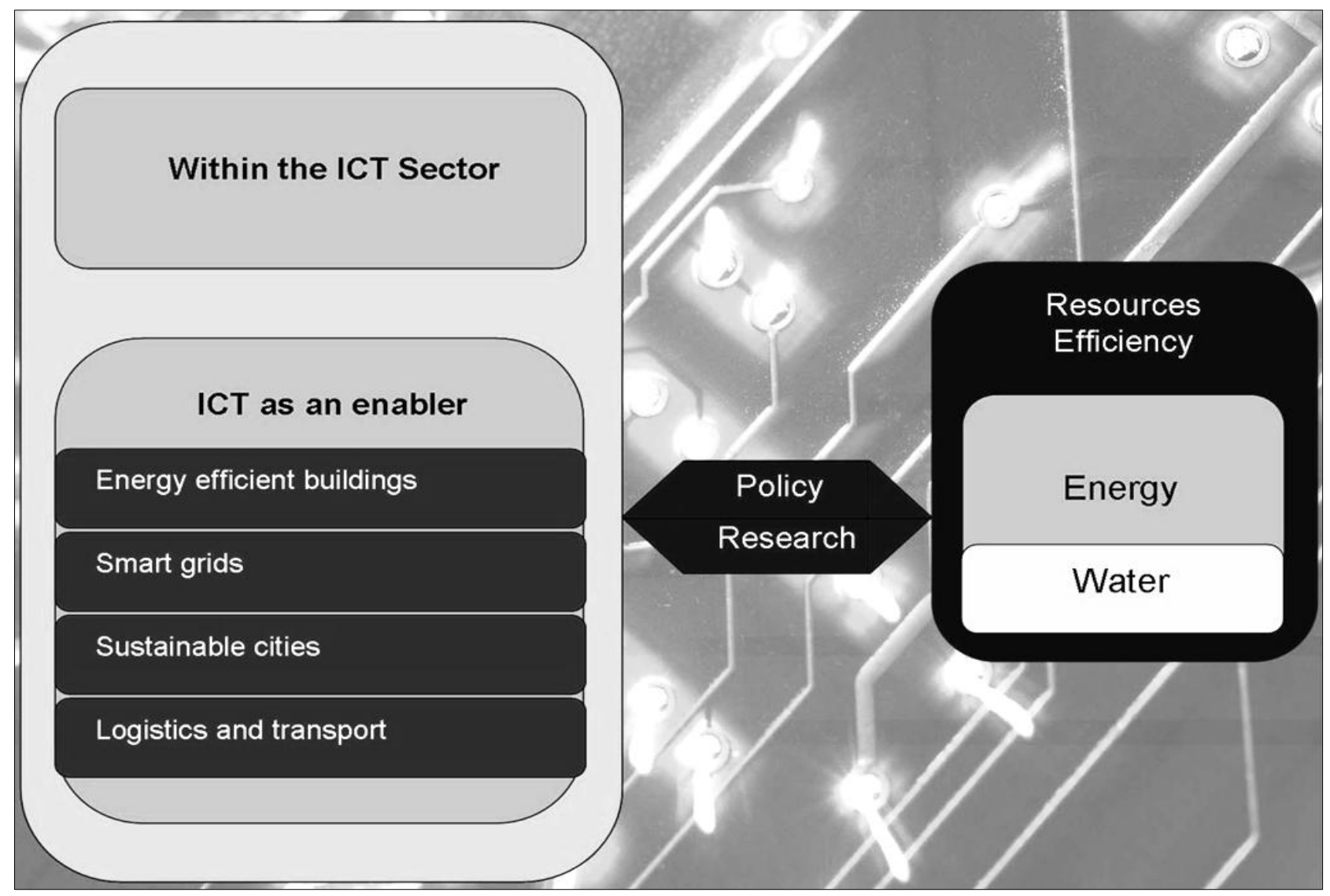

Fig. 1. Activity areas of EU funding on information society development

In the project framework 2007-2013 EU has enlarged funding that support of information society as the impact has been proven. Focus groups have been developed and metrics established to follow the impact of EU funding on information society development (see Fig. 1). Based on that, recommendations have been made to pin point the activity areas (European Commission, 2012). 


\section{Conclusion}

In Fig. 2, which we obtained and the way we aligned the values of components on $x$ axis, we have presented aligned values of the component 1 , whereas on $y$ axis the aligned values of component 2; we can see that EU-15 countries are divided into approximately five groups as follows:

$1^{\text {st }}$ Group: Italy, Spain, Greece and Portugal

$2^{\text {nd }}$ Group: France, Germany, United Kingdom

$3^{\text {rd }}$ Group: Belgium, Austria

$4^{\text {th }}$ Group: Luxemburg, Ireland, Finland

$5^{\text {th }}$ Group: Netherland, Denmark, Sweden

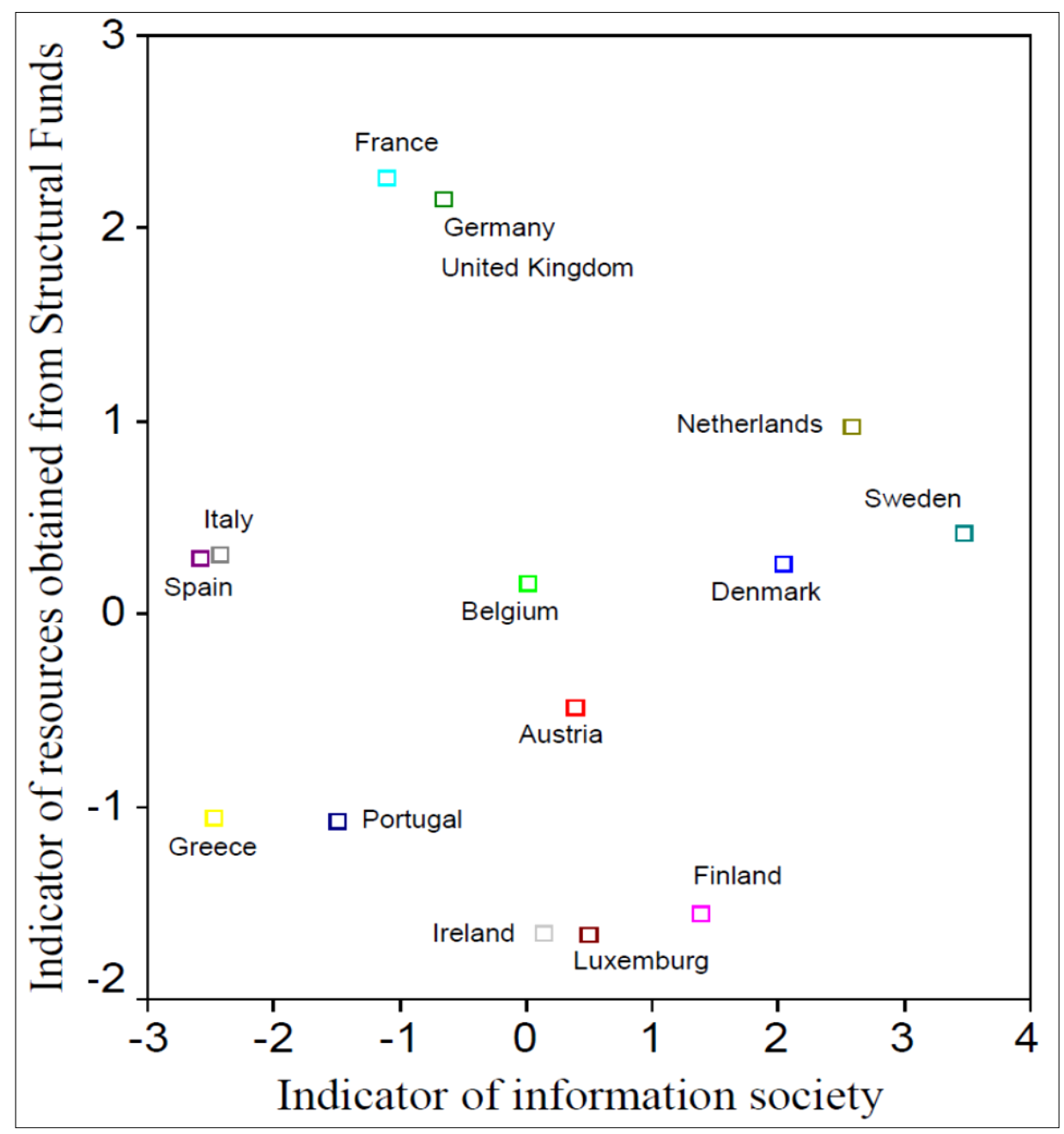

Fig. 2. Components of information society (1) and European Structural Fund (2)

$1^{\text {st }}$ Group includes countries, which according to economic indicators are less developed, medium-sized, or large, or small receivers (in the relative term in relation to GDP) to resources from Structural Funds and are relatively low information developed. Italy is absolutely the biggest receiver of EU funds in 2002.

$2^{\text {nd }}$ Group comprises the biggest EU-15 countries, economically above the average, but regionally unequally developed and big users of Structural Funds (Germany due to transfers in former East Germany, and France due to poor 
Kafol, C.: Positioning of EU-15 Member States in Accordance with the Developm...

development in the rural regions). The IT indicators for development for all show an average value.

In $3^{\text {rd }}$ Group are countries, which are average information developed and medium users of Structural Funds. The two smaller countries, Belgium and Austria, due to their small dimensions and relatively balanced development of regions get lower financial resources (in absolute number) from the Structural Funds.

$4^{\text {th }}$ Group includes smaller countries with a significant surplus in ICT trade deficit and relatively good level of information society development. Ireland is known in EU-15 as a successful receiver of Structural Funds and even the biggest exporter of ICT in EU-15. This is a group of the above of average well economically developed countries with a successful ICT industry.

$5^{\text {th }}$ Group comprises countries, which are in the first row of IT development and among the best, or the best in the information society development. They are relatively small receivers of resources from the EU Structural Funds, or they are big net-payers in the Funds.

In principle it can be assumed that the information society is the best developed (according to an indicator of resources obtained) in Luxemburg, Ireland, Finland, Netherland, Denmark, and Sweden. France, Germany, Belgium, the United Kingdom, and Austria are on average. Under average results have been achieved in Italy, Greece, Spain, and Portugal.

The EU funds are allocated inverse proportionally with the development of information society and this according to convergent purpose is right.

\section{Appendix - Results from calculations (Factorial Analysis) - complete process}

\begin{tabular}{|l|r|r|r|r|r|}
\hline & N & Minimum & Maximum & \multicolumn{1}{c|}{ Mean } & Std. Dev iation \\
\hline EU_SKL & 15 &, 44 & 82,26 & 25,2025 & 26,80731 \\
TB_GDP & 15 & $-9535,00$ & 8407,00 & $-1075,60$ & 4418,42008 \\
ST_INT & 15 & 19,00 & 57,00 & 38,2000 & 10,67172 \\
ST_MOB & 15 & 65,00 & 101,00 & 82,0000 & 8,79935 \\
ST_INT_G & 15 & 14,00 & 68,00 & 47,1333 & 15,48209 \\
ST_RAC_S & 15 &, 50 & 3,30 & 1,8333 &, 77059 \\
E_GOV & 15 & 40,00 & 71,00 & 52,1333 & 8,88712 \\
Valid N (listwise) & 15 & & & & \\
\hline
\end{tabular}

Tab. 2. Descriptive statistics (1)

\begin{tabular}{|l|r|r|r|}
\hline & \multicolumn{1}{|c|}{ Mean } & Std. Deviation & Analysis N \\
\hline ZEU_SKL1 &, 0000 & 1,00000 & 15 \\
ZTB_GDP &, 0000 & 1,00000 & 15 \\
ZST_INT &, 0000 & 1,00000 & 15 \\
ZST_MOB &, 0000 & 1,00000 & 15 \\
ZST_IN_A &, 0000 & 1,00000 & 15 \\
ZST_RAC &, 0000 & 1,00000 & 15 \\
ZE_GOV &, 0000 & 1,00000 & 15 \\
\hline
\end{tabular}

Tab. 3. Descriptive statistics (2) 


\begin{tabular}{|ll|r|r|r|r|r|r|r|}
\hline & & ZEU SKL1 & ZTB GDP & ZST INT & ZST MOB & ZST IN A & ZST_RAC & ZE_GOV \\
\hline Correlation & ZEU_SKL1 & 1,000 &,- 616 &,- 219 &,- 352 &,- 300 &,- 172 &,- 064 \\
& ZTB_GDP &,- 616 & 1,000 &, 389 &,- 009 &, 525 &, 367 &,- 023 \\
& ZST_INT &,- 219 &, 389 & 1,000 &, 056 &, 747 &, 848 &, 495 \\
& ZST_MOB &,- 352 &,- 009 &, 056 & 1,000 &, 034 &,- 072 &,- 129 \\
& ZST_IN_A &,- 300 &, 525 &, 747 &, 034 & 1,000 &, 876 &, 497 \\
& ZST_RAC &,- 172 &, 367 &, 848 &,- 072 &, 876 & 1,000 &, 657 \\
& ZE_GOV &,- 064 &,- 023 &, 495 &,- 129 &, 497 &, 657 & 1,000 \\
\hline Sig. (1-tailed) & ZEU_SKL1 & &, 007 &, 217 &, 099 &, 139 &, 270 &, 410 \\
& ZTB_GDP &, 007 & &, 076 &, 487 &, 022 &, 089 &, 468 \\
& ZST_INT &, 217 &, 076 & &, 422 &, 001 &, 000 &, 030 \\
& ZST_MOB &, 099 &, 487 &, 422 & &, 453 &, 400 &, 324 \\
& ZST_IN_A &, 139 &, 022 &, 001 &, 453 & &, 000 &, 030 \\
& ZST_RAC &, 270 &, 089 &, 000 &, 400 &, 000 & &, 004 \\
& ZE_GOV &, 410 &, 468 &, 030 &,, 324 &, 030 &, 004 & \\
\hline
\end{tabular}

a. Determinant $=, 008$

Tab. 4. Correlation matrix

\begin{tabular}{|c|c|c|}
\hline \multicolumn{2}{|c|}{$\begin{array}{l}\text { Kaiser-Mey er-Olkin Measure of Sampling } \\
\text { Adequacy. }\end{array}$} & 633, \\
\hline $\begin{array}{l}\text { Bartlett's Test of } \\
\text { Sphericity }\end{array}$ & $\begin{array}{l}\text { Approx. Chi-Square } \\
\text { df } \\
\text { Sig. }\end{array}$ & $\begin{array}{r}51,834 \\
21 \\
, 000\end{array}$ \\
\hline
\end{tabular}

Tab. 5. KMO and Barlett's test

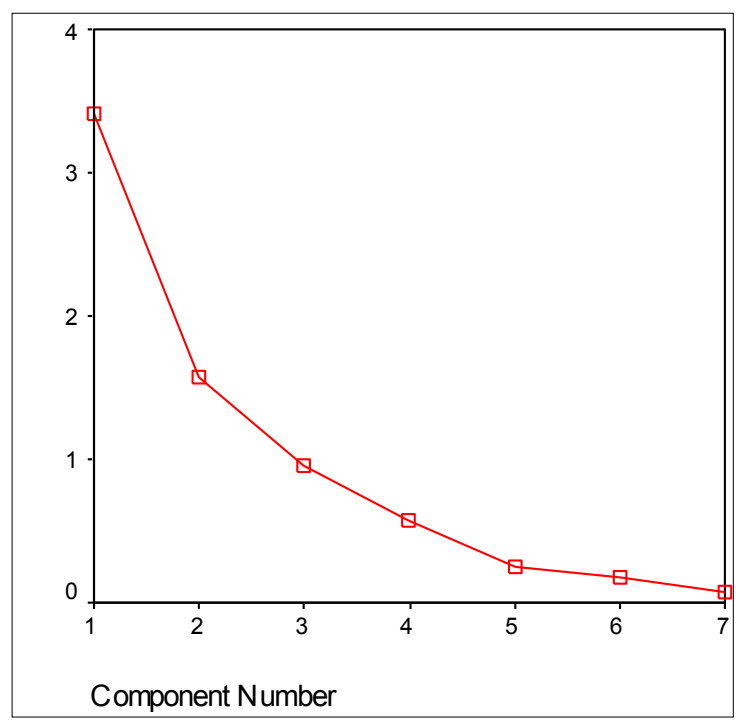

Fig. 3. Screen plot: Eigenvalue / Component number

\begin{tabular}{|l|r|r|r|}
\hline & \multicolumn{2}{|c|}{ Component } & \\
\cline { 2 - 4 } & \multicolumn{1}{|c|}{1} & \multicolumn{1}{|c|}{2} & Extraction \\
\hline ZEU_SKL1 &,- 432 &, 768 &, 776 \\
ZTB_GDP &, 587 &,- 560 &, 659 \\
ZST_INT &, 876 &, 116 &, 781 \\
ZST_MOB &, 033 &,- 590 &, 349 \\
ZST_IN_A &, 921 &, 028 &, 849 \\
ZST_RAC &, 932 &, 262 &, 938 \\
ZE_GOV &, 628 &, 491 &, 636 \\
\hline
\end{tabular}

Tab. 6. Two components matrix (left) and communalities (right) (extraction method: Principal Component Analysis) 
Kafol, C.: Positioning of EU-15 Member States in Accordance with the Developm...

\begin{tabular}{|l|r|r|r|}
\hline \multirow{2}{*}{ Component } & \multicolumn{3}{|c|}{ Extraction Sums of Squared Loadings } \\
\cline { 2 - 4 } & Total & \% of Variance & Cumulative $\%$ \\
\hline 1 & 3,412 & 48,750 & 48,750 \\
2 & 1,576 & 22,515 & 71,265 \\
\hline
\end{tabular}

Tab. 7. Total variance explained (extraction method: Principal Component Analysis)

\begin{tabular}{|c|c|c|c|c|c|}
\hline & \multicolumn{2}{|c|}{ Component } & & & \\
\hline & 1 & 2 & & & \\
\hline ZEU_SKL1 &,- 127 & ,487 & & & \\
\hline ZTB_GDP & , 172 &,- 356 & & & \\
\hline ZST_INT & ,257 & ,074 & & & \\
\hline ZST_MOB & , 010 &,- 374 & & & \\
\hline ZST_IN_A & ,270 & , 018 & Component & 1 & 2 \\
\hline ZST_RAC & ,273 & , 166 & 1 & 1,000 &, 000 \\
\hline ZE_GOV & 184 & ,312 & 2 & ,000 & 1,000 \\
\hline
\end{tabular}

Tab. 8. Component score coefficient (left) and covariance (right) matrices (extraction method: Principal Component Analysis)

\section{References}

Boldrin, M. \& Canova, F. (2001). Inequality and Convergence in Europe's Regions: Reconsidering European Regional Policies. Economic Policy, Vol. 32, 6-17

European Commission (2001). Structural Funds and the Information Society. http://europa.eu.int/informationsociety/structuralfunds.htm, accessed on 10-102011

European Commission (2003). Information society statistics, Data 1997-2002

European Commission (2004): Draft chapter 2 of European Economy: Catching-up, growth and convergence of the new member

European Commission (2012). Information Society. http://ec.europa.eu/information_ society/activities/sustainable_growth/policy/index_en.htm, accessed on 9-072012

Eurostat - European Union Commission (2002). Statistics on the information society in Europe, Luxembourg, Office for Official Publications of the EC

Gerling, K. M. (2002). Subsidization and Structural Change in Eastern Germany. Springer Verlag, Berlin, 17-24

Midelfart, K. H. (2004). Regional Policy Design: An Analysis of Relocation, Efficiency and Equity. CEPR Discussion Paper No. 4321, London, 432-465

Office for official publications of the European Communities (2001). Financial Report 2000, http://europa.eu.int/statistics/budgetexecute2001.pdf, accessed on 10-10-2011

Worthington, T. (2011). ICT Sustainability: Assessment and Strategies for a Low Carbon Future. LuLu Press, Raleigh, North Carolina 